Revista Oficial del Poder Judicial

ÓRGANO DE INVESTIGACIÓN DE LA CORTE SUPREMA DE JUSTICIA DE LA REPÚBLICA DEL PERÚ

Vol. 12, n. ${ }^{\circ}$ 14, julio-diciembre, 2020, 61-91

ISSN versión impresa: 1997-6682

ISSN versión online: 2663-9130

DOI: https://doi.org/10.35292/ropj.u12i14.265

\title{
Los tribunales constitucionales frente a la emergencia sanitaria por la COVID-19
}

The Constitutional Courts in the face of the Health Emergency due to COVID-19

(1)

JESÚS ÁNGEL CADENA ALCALÁ

Tribunal Electoral del Poder Judicial de la Federación en México

(Ciudad de México, México)

Contacto: jesus.cadenaa@te.gob.mx

https://orcid.org/0000-0002-6676-6880

\begin{abstract}
RESUMEN
El presente texto tiene por objeto analizar la posición privilegiada de los tribunales constitucionales frente a la custodia integral y la estabilidad de los textos constitucionales. Los recientes escenarios a nivel mundial han puesto de manifiesto la necesidad de que dichos tribunales respondan a las exigencias sociales, sobre todo, cuando el actuar de los poderes públicos tiende a menoscabar el ejercicio adecuado y eficaz de los derechos, libertades y principios reconocidos en los textos constitucionales y en el derecho internacional de los derechos humanos. Para ellos la interpretación y argumentación constitucional es un bastión que les permite analizar la validez de los actos de los poderes públicos en su búsqueda
\end{abstract}


por contener sus actuaciones, aunque estas limiten o restrinjan derechos fundamentales y resulten, por tanto, contrarias a los valores sobre los que se sustenta el Estado constitucional de derecho.

Palabras clave: tribunales constitucionales, derechos fundamentales, restricciones al ejercicio de derechos y libertades, pandemia, COVID-19.

\section{ABSTRACT}

The purpose of this text is to analyse the privileged position of the constitutional courts in regards to the full custody and stability of constitutional texts. Recent world scenarios have shown the need for such courts to respond to social demands, especially when the actions of public authorities tend to undermine the proper and effective exercise of the rights, freedoms and principles recognized in constitutional texts and international human rights law. For them, the interpretation and constitutional argumentation is a bastion with which they can analyze the validity of the acts of the public powers that limit or restrict fundamental rights, seeking to contain their actions when they are contrary to the values on which it is based the constitutional State of Law.

Key words: Constitutional Courts, fundamental rights, restrictions on the exercise of rights and freedoms, health pandemic by COVID-19.

Recibido: 29/10/2020 Aceptado: 05/11/2020

\section{INTRODUCCIÓN}

¿En tiempos contemporáneos cómo deben actuar los tribunales constitucionales para garantizar el ejercicio de los derechos fundamentales? Sin duda, esta es una de las grandes interrogantes que se presentan en las sociedades democráticas, más aún cuando nos enfrentamos a contextos tan poco alentadores como la pandemia 
sanitaria por la COVID-19 que se vive recientemente en el mundo. El rol de los tribunales constitucionales necesita un incentivo mayúsculo y ello puede visualizarse a través de la protección efectiva y eficaz de los derechos fundamentales y la preservación del Estado de derecho. Dichos elementos generan condiciones adecuadas para la consolidación de la Ley Fundamental y su posición primigenia o preponderante en el sistema normativo de los Estados constitucionales de derecho.

El presente artículo se distingue por el análisis de tres aspectos predominantes que están presentes en el constitucionalismo contemporáneo: la protección y defensa de los derechos fundamentales por los jueces constitucionales, el proceder de los tribunales constitucionales como contrapeso al actuar de los poderes públicos, y su actuación ante nuevas exigencias sociales que reclama un ejercicio interpretativo evolutivo, consecuencialista y principista.

Diversos cuestionamientos surgen al analizar tales tópicos de relevancia constitucional, como ¿cuál es la función del juez constitucional en la protección efectiva de los derechos fundamentales?, ¿de qué metodologías contemporáneas debe auxiliarse?, ¿cuál es la posición de los tribunales constitucionales frente al actuar de los poderes públicos?, ¿cómo deben actuar ante situaciones anormales que pongan en riesgo la estabilidad de los textos constitucionales?, ¿qué técnicas de interpretación constitucional deben emplearse para responder a las nuevas exigencias sociales?, y ¿cómo se han comportado los tribunales constitucionales ante las limitaciones o restricciones al ejercicio de derechos fundamentales que han surgido ante la pandemia sanitaria por COVID-19?

Sin el ánimo de dar respuestas inapelables a las interrogantes que se plantean, pretendo abordar la necesidad de contar con tribunales constitucionales reactivos, racionales y coherentes que, ante el dictado de estados de emergencia, alarma o excepción, ejerzan 
sus funciones y atribuciones constitucionales para evitar que los contextos sociales anormales produzcan límites o restricciones arbitrarios al ejercicio de los derechos fundamentales.

\section{LA DEFENSA DE DERECHOS FUNDAMENTALES POR LOS JUECES CONSTITUCIONALES. UNA RELACIÓN PROPIA DEL CONSTITUCIONALISMO REMATERIALIZADO}

Durante el periodo sucesivo a la Segunda Guerra Mundial, las constituciones en el mundo, principalmente en Occidente, se dieron a la tarea de incluir una serie de normas sustantivas destinadas principalmente a proteger los derechos fundamentales de las personas. Así, las dotaron de la máxima jerarquía normativa y de instrumentos como pautas autoaplicativas cuyo reconocimiento constitucional basta para generar una observancia o vinculación de cumplimiento hacia todas las autoridades en el Estado constitucional contemporáneo.

Este fenómeno de rematerialización constitucional, según señala Prieto Sanchís (2013), comprende:

no solo la incorporación de normas formales, de competencia o de procedimiento, sino también, normas sustantivas, que pretenden trazar límites negativos y vínculos positivos principalmente para los poderes públicos, construidos como valores superiores, principios y derechos fundamentales (p. 26).

Así, es claro que el nuevo orden constitucional contemporáneo (sustantivo) no debe entenderse en términos taxativos, sino que está destinado a enriquecerse por el quehacer especialmente de los tribunales constitucionales que, a través de la interpretación constitucional principista, incorporan o crean «nuevos derechos» (Pino, 2018, p. 38). Bajo esa premisa, surge una primera interrogante: ¿a qué agente del Estado constitucional contemporáneo 
le corresponde por excelencia la tutela y defensa de los derechos fundamentales?

Sin duda, el juez constitucional asume la tarea primigenia de protección de los derechos fundamentales, es decir, de aquellas normas de producción sustantiva previstas en el orden constitucional, que requieren de múltiples garantías judiciales para controlar (limitar) tanto el actuar de los poderes públicos como el de los actores del derecho privado, dada la relevancia objetiva y subjetiva que presentan los textos constitucionales. Como lo sostiene Giorgio Pino (2018), la centralidad del Poder Judicial contrae la administración de los derechos fundamentales, lo que se configura como una «tarea compleja que tiene como propios protagonistas no solo al legislador y a la administración, sino también a los jueces, tanto constitucionales como comunes» (p. 41).

$\mathrm{Al}$ asumir dicha labor preponderante, ¿qué modelo de Estado constitucional contemporáneo es acorde con la labor de protección principista?, ¿cuáles son las dimensiones sustantivas que deben advertir los jueces constitucionales en la protección de los derechos fundamentales?, y ¿qué herramientas interpretativas y argumentativas debe acoger el juez constitucional para ofrecer una tutela judicial efectiva e integral?

\subsection{El pospositivismo y el modelo de Estado constitucional de los principios}

Uno de los postulados filosóficos más relevantes del pospositivismo es la distinción entre reglas y principios constitucionales. A respecto, Josep Aguiló Regla (2007) señala que en el constitucionalismo los principios:

dotan de sentido a las reglas. Permiten verlas, por un lado, como instrumentos para la protección y promoción de ciertos bienes (valores) jurídicos y, por otro, como resultado de un «balance, 
ponderación o compromiso» entre principios para el caso (genérico) que ellas regulan» (pp. 669-670).

A propósito de dicha relación, los principios van condicionando la aplicación de las reglas con el objeto de que tengan una relación de regularidad con los elementos axiológicos que se tutelan desde el orden constitucional. Además, las reglas también se aprecian como normas no escritas (concretización) para generar la aplicación del principio que eventualmente resultó vencedor derivado de un ejercicio ponderativo. Manuel Atienza (2017) sostiene que en el Estado constitucional el vínculo entre reglas y principios es eminente, por lo que se necesita:

conjugar reglas y principios y buscar, por así decirlo, un equilibrio entre la certeza que procuran las reglas y la flexibilidad que requiere el manejo inteligente del material jurídico y que no es posible llevar a cabo sin los principios: es precisamente en los principios en donde se encuentra la justificación para aceptar en algunos casos la existencia de excepciones -implícitas, no formuladas en el texto de la ley—a las reglas (p. 140).

El sano equilibrio entre reglas y principios brinda certeza jurídica a la vigencia y aplicación de las normas integrantes en los sistemas constitucionales, al grado de que su correcta aplicación provoque ajustes razonables de actualización normativa (prescriptiva y descriptiva).

Otro de los factores relevantes del pospositivismo es la lectura moral de los textos constitucionales debido a la inclusión de principios abstractos que tienden a proteger diversos derechos fundamentales inherentes a la condición natural de la persona. Sobre el particular, Ronald Dworkin (2019) señala que, «según la moral, estas cláusulas (constitucionales) deben ser entendidas de la forma que más naturalmente sugiere su redacción: se refiere a 
principios morales abstractos y los incorpora por referencia, como límites al poder del Gobierno» (p. 14). No obstante, es preciso acotar dicha lectura moral objetiva a normas sustantivas de naturaleza abstracta, mas no a la totalidad de las cláusulas constitucionales. Para lograrlo, el juez constitucional debe concebirse como un agente filosófico que conoce el contenido esencial de los derechos fundamentales, su espectro de protección y sus límites proporcionales susceptibles de configurarse a través de la libertad configurativa del legislador democrático.

Finalmente, hablar de pospositivismo es dejar de lado el formalismo y el activismo judicial para adentrarnos en el análisis de las posibilidades normativas y fácticas que posee un juez activo en la defensa de los derechos, libertades, principios y valores de orden constitucional. Así, el juez constitucional podrá definirse como un «juez argumentativo que toma en serio la obligación de fundamentar sus decisiones, y, por ello, acepta también la existencia de ciertos límites: los que marcan la diferencia entre lo que es y lo que no es argumentable en el Derecho» (Atienza, 2017, p. 142). Y esto no es únicamente aplicable al derecho, pues debe buscar crear derecho a partir de sus determinaciones, y doblegar así la idea de que solamente es un mero anulador o invalidador de aquellas normas contrarias a los clausulados constitucionales.

Las sentencias constitucionales, para estar debidamente construidas y legitimadas, requieren de un argumento de coherencia y dinamismo que despliegue su justificación interna y externa, a fin de lograr en alguna medida la satisfacción de sus receptores y eventuales críticos.

\subsection{La dimensión constitucional y supranacional principista}

La conformación de los textos constitucionales no se limita a su configuración expresa o implícita (interpretativa-creativa) desde su concepción doméstica, sino que también contempla la 
inclusión de normas de derecho internacional que, prima facie, reconocen el contenido esencial de un derecho o libertad; además, prevé las interpretaciones que al efecto realizan tanto los jueces constitucionales como los encargados de la protección de derechos humanos a nivel internacional (regionales). Dicha reordenación constitucional, sin duda, busca afianzar la supremacía constitucional de las convenciones y tratados de derechos humanos (Sagüés, 2011, p. 147).

En ese sentido, la defensa de las normas sustantivas, a razón del reconocimiento de derechos, libertades, principios y valores, posee un espectro expansivo conformado por las garantías de protección previstas tanto en el texto constitucional como en el derecho internacional de los derechos humanos, las mismas que generan una plenitud deóntica con el ejercicio de las cláusulas constitucionales (Ferrajoli, 2014, pp. 58-59).

Aunado al reconocimiento de garantías de protección para materializar el ejercicio de las normas sustantivas, la inserción constitucional del derecho internacional de los derechos humanos provoca una convergencia interpretativa a la hora de definir el contenido esencial de los derechos, libertades, principios y valores por parte de los jueces constitucionales, los que están sujetos a la aplicación del control de convencionalidad.

Bajo esas premisas, la lectura ampliada y no taxativa del texto constitucional conforma un bloque de constitucionalidad que sirve de parámetro de control de la constitucionalidad de los enunciados normativos y demás actos que transgredan el ejercicio de una norma que, desde una posición primigenia, reconozca algún derecho, libertad, principio o valor (Ferrer Mac-Gregor, 2017, p. 671). Este control jurídico que realiza el juez constitucional tiene como objetivo salvaguardar la prevalencia y estabilidad de la Ley Fundamental no solo desde la perspectiva doméstica, sino también desde una 
visión supranacional que vela por el estricto cumplimiento de los derechos de orden internacional, en tanto aquellos sean aceptados y ratificados por los Estados.

La dimensión supranacional es pieza clave para la actualización de un transconstitucionalismo que concibe al juez constitucional como un guardián convencionalizado cuya principal defensa recae en salvaguardar el efecto útil de los tratados internacionales y garantizar la aplicación interpretativa adecuadora de la norma nacional frente al corpus iuris interamericano.

\subsection{La interpretación y argumentación principista}

Como se ha sostenido a lo largo del presente texto, la inserción de normas sustantivas en los textos constitucionales requiere de la reformulación de los métodos de interpretación y argumentación principista. El silogismo subsuntivo resulta un método inacabado para resolver los conflictos que se generan entre derechos, libertades, principios y valores. Por ello, la ponderación:

se ha convertido en un criterio metodológico indispensable para el ejercicio de la función jurisdiccional, especialmente la que se desarrolla en los Tribunales Constitucionales, que se encargan de la aplicación de normas que, como los derechos fundamentales, tienen la estructura de principios (Bernal, 2003, p. 5).

La teoría relativa presupone la posibilidad de que el contenido esencial de los derechos, libertades, principios y valores se fije de manera casuística estableciendo cuáles son sus límites razonables y necesarios, es decir, admisibles constitucionalmente, los mismos que busquen en todo momento la extensión más amplia posible para su ejercicio. En ese sentido, la aplicación de la ponderación y la proporcionalidad como métodos de interpretación y argumentación principista resulta imprescindible (Silva, 2012, p. 23). 
Así, la actuación del juez constitucional resulta imperativa para atender el contenido de los principios como normas limitables o restringibles, a través del empleo de la ponderación para resolver conflictos o tensiones individuales (personales) entre normas con contenido que, prima facie, resultan incompatibles, o bien mediante la implementación del principio de proporcionalidad que permite verificar la validez constitucional de una restricción general frente a la posible afectación de un principio.

La ponderación implica que los enunciados que operen como mandatos de optimización ordenen «que algo sea realizado en la mayor medida posible, dentro de las posibilidades jurídicas y reales existentes» (Alexy, 1993, pp. 86-87). Por otra parte, el principio de proporcionalidad "constituye hoy en día quizá el más conocido y el más recurrente "límite de los límites" a los derechos fundamentales y en esa medida supone una barrera frente a intromisiones indebidas en el ámbito de los propios derechos» (Carbonell, 2008, p. 10).

En tal virtud, tanto la ponderación como la proporcionalidad son metodologías contemporáneas para resolver casos de conflictos normativos en los que se encuentre en juego el contenido esencial de algún derecho, libertad, principio o valor de jerarquía constitucional previsto en el bloque de constitucionalidad. Dichos problemas normativo-interpretativos se presentan como problemas de relevancia o clasificación que requieren de un argumento consecuencialista y principista para ofrecer una solución jurídica debidamente razonada, fundada y motivada (MacCormick, 2018, pp. 248-249).

Por lo tanto, la tarea del juez constitucional será resolver cuestiones como ¿qué argumentos principistas son idóneos para solucionar el caso sometido a su conocimiento?, ¿qué metodología contemporánea debe utilizar para ofrecer una 
respuesta suficientemente legitimada?, y ¿si el papel de juez activo es paralelo a la protección de los derechos fundamentales?

A partir de las premisas anunciadas es dable proponer que la tarea del juez constitucional será valorizar el caso de relevancia planteado desde dos perspectivas: (i) la filosófica-dogmática, para visualizar, prima facie, la naturaleza de la norma constitucional; y (ii) la jurídica, para brindar una respuesta interpretativo-normativa coherente, es decir, "sujeta a una exigencia de racionalidad» ante un eventual conflicto o colisión normativa de naturaleza sustantiva (Gascón, 2014, p. 319).

\section{LOS TRIBUNALES CONSTITUCIONALES Y SU QUEHACER COMO CONTRAPESO AL ACTUAR LOS PODERES PÚBLICOS}

Hans Kelsen (2017), en su propuesta científica para la implementación de los tribunales constitucionales (Verfassungsgerichtsbarkeit), dispuso que dichos órganos autónomos del parlamento y de cualquier otra autoridad estatal sean los encargados de anular aquellos actos o normas generales inconstitucionales, con el fin de defender la regularidad de la Constitución (pp. 29 y 37). Así, el principio de constitucionalidad es el que somete el actuar del legislador sujetándolo a su cumplimiento y observancia irrestricta (Zagrebelsky, 2020, p. 729).

Dicho principio, apoyado del progreso del derecho procesal orgánico y de la libertad, ha revolucionado la actuación de los tribunales constitucionales ante la obligación de tutelar el ejercicio de normas de contenido prima facie, ya que no basta con que anulen o invaliden aquellos actos o normas generales que las contradigan - lo que los constituiría en una especie de legisladores negativos-, sino que también deben pugnar por la inserción de nuevos derechos que actualicen el contenido constitucional, dando pauta para que dichos tribunales se conviertan en una especie de legislador positivo. 
Tomando en cuenta esa visión disruptiva y no taxativa, la justicia constitucional empezó a tener como misión primigenia la defensa de la constitución y de sus valores democráticos, así como sus principios fundamentales, además de los derechos y garantías en ella consagradas (Ferrer Mac-Gregor y Zaldívar, 2008, p. 832). Así, la función contenedora y controladora que, de origen, dio vida a los tribunales constitucionales para limitar racionalmente el poder político transitó hacia un proyecto innovador y creativo que propone una lectura integral en la protección de los derechos fundamentales, situando a dichos tribunales como agentes de cambio social.

Diversos son los elementos que mutaron para la actualización de los tribunales constitucionales, entre los que se destacan (i) el transitar del Estado liberal hacia un Estado social y constitucional, cuyo fin transcendental es la protección subjetiva y objetiva del contenido constitucional; (ii) la rematerialización del contenido constitucional para situar en jerarquía preponderante a diversos derechos, libertades, principios y valores, y (iii) la reformulación de sus funciones y atribuciones para concebirlos como los auténticos guardianes de los aspectos sustantivos en los Estados constitucionales de derecho.

Sin duda, la función creativa del juez constitucional está íntimamente relacionada con la defensa efectiva de los derechos fundamentales; tal como sostiene Eduardo Ferrer Mac-Gregor (2017), «en la actualidad parecen irrefutables los argumentos [...] a favor de la legitimidad creadora de los jueces [...] debido a la rica interpretación de las normas fundamentales por parte de los Tribunales Constitucionales de nuestro tiempo» (p. 168). Esta verdadera función productora es la que nos sitúa en la siguiente interrogante: ¿cómo deben actuar los tribunales constitucionales ante nuevas exigencias o realidades sociales?

La pandemia por la COVID-19 ejemplifica el perfecto escenario en el que la actividad de los tribunales constitucionales resulta 
imprescindible para evitar abusos en el ejercicio del poder político, al tenor de la posibilidad de suspender, restringir o limitar el ejercicio de los derechos fundamentales. Los Estados, a través de las diversas facultades constitucionales, han dictado estados de emergencia o alarma sanitaria para poder contener los efectos devastadores de la crisis que se vive actualmente en el mundo.

El Poder Ejecutivo ha intentado legitimar su actuación mediante la ejecución de medidas restrictivas o suspensivas del contenido esencial de múltiples derechos fundamentales, en aras de garantizar el derecho a la salud de todas las personas. Sirve de ejemplo a lo aseverado, el análisis de los decretos de emergencia o alarma sanitaria dictados por algunos Estados, los que se presentarán a continuación.

\subsection{Colombia}

El 12 de marzo del año en curso el Ministerio de Salud y Protección Social, de acuerdo con lo establecido en el artículo 69 de la Ley n. 1753 de 2015, declaró el estado de emergencia sanitaria por COVID-19, y con dicho decreto se restringieron o limitaron los siguientes derechos fundamentales: (i) reunión o asociación; (ii) trabajo, comercio o empresa; (iii) libre tránsito; (iv) religión o culto; (v) educación de manera presencial, entre otros.

Sumado a lo anterior, los decretos n. ${ }^{\text {os }} 417$ y 457 del 17 y 22 de marzo, respectivamente, emitidos por el Poder Ejecutivo, sirvieron de sustento para dictar también un estado de emergencia económica, social y ecológica en todo el territorio nacional, los que buscaron establecer bases formales y de ejecución para mitigar los efectos de la pandemia sanitaria. Asimismo, se emitieron las directrices $n .{ }^{\text {os }} 02$ y 002 con medidas de prevención y contención de la pandemia sanitaria existente, destinadas a establecer el uso de las tecnologías de la información y las telecomunicaciones, así como para instaurar una guía de actuación para las instituciones 
o poderes públicos del Estado en aras de garantizar el derecho a la salud de sus funcionarios.

\subsection{Costa Rica}

El pasado 16 de marzo, el Gobierno de Costa Rica, por conducto de la Presidencia y el Ministerio de Salud, emitió el Decreto n. ${ }^{\circ}$ 42227MP-S, mediante el cual se dictó el estado de emergencia nacional en todo el territorio nacional debido a la pandemia de la COVID-19. Dicho decreto tuvo como fundamento lo previsto en los incisos 6 y 8 del artículo 140, y los artículos 146 y 180 de la Constitución Política, así como los artículos 18 y 29 de la Ley Nacional de Emergencia y Prevención del Riesgo.

Al tenor de la determinación adoptada y al margen del Decreto n. ${ }^{\circ}$ 42221-S, así como de la Directriz n. ${ }^{\circ}$ 074-S, emitidos el 10 y 12 de marzo, respectivamente, se restringió el ejercicio de los siguientes derechos fundamentales: (i) reunión o asociación; (ii) libre tránsito; (iii) educación; (iv) trabajo, comercio y empresa de manera presencial, entre otros. Dichas limitaciones buscan cumplir con un fin constitucionalmente legítimo, representado por la protección del derecho a la salud y la mitigación de los efectos de la pandemia sanitaria.

\subsection{España}

El estado de alarma generado por el Gobierno español tuvo lugar en el Real Decreto n. ${ }^{\circ}$ 463/2020, del 14 de marzo de 2020, generado debido a la situación de crisis sanitaria ocasionada por la COVID-19. Con dicho decreto se limitaron o restringieron parcialmente los siguientes derechos y libertades: (i) tránsito; (ii) educación; (iii) de comercio o empresarial; (iv) trabajo; (v) culto; (vi) reunión o asociación; (vii) manifestación, y (viii) acceso a la justicia o tutela judicial efectiva (lo que implicó la suspensión o interrupción de plazos procesales). 
Lo conducente tuvo como fundamento el artículo 116.2 de la Constitución española, así como el apartado b) del diverso cuarto de la Ley Orgánica n. ${ }^{\circ}$ 4/1981, del 1 de junio (sobre los estados de alarma, excepción y sitio). Así pues, el estado de alarma de mérito no supone la suspensión de ningún derecho fundamental, tal y como prevé el artículo 55 de la propia Constitución.

\subsection{México}

En el caso del Estado mexicano, el artículo 73 (fracción XVI, numerarias 1. ${ }^{\mathrm{a}}$ a $4 .{ }^{\mathrm{a}}$ ) de la Constitución Federal establece que el Consejo de Salubridad General dictará las medidas preventivas indispensables para enfrentar una epidemia sanitaria, las cuales serán sancionadas posteriormente por el presidente de la República. Para ello, implícitamente, habrá de conformarse un estado de emergencia sanitaria susceptible de imponer ciertos límites o restricciones al ejercicio de los derechos fundamentales, a través de un fin constitucionalmente imperioso, como lo es la protección del derecho a la salud.

Entre los múltiples decretos que ha dictado el Ejecutivo Federal destacan los conducentes:

i) Acuerdo por el que se establecen las medidas preventivas que se deberán implementar para la mitigación y control de los riesgos para la salud que implica la enfermedad por el virus SARS-CoV2 (COVID-19), publicado en el Diario Oficial de la Federación el 24 de marzo de 2020.

ii) Decreto por el que se declaran acciones extraordinarias en las regiones afectadas de todo el territorio nacional en materia de salubridad general para combatir la enfermedad grave de atención prioritaria generada por el virus SARS-CoV2 (COVID-19), publicado en el Diario Oficial de la Federación el 27 de 2020. 
iii) Acuerdo por el que se establecen acciones extraordinarias para atender la emergencia sanitaria generada por el virus SARSCoV2, publicado en el Diario Oficial de la Federación el 31 de marzo de 2020; y acuerdo que lo modifica, publicado en el mismo medio el 21 de abril del mismo año.

Dichos decretos limitaron explícita o implícitamente las libertades de reunión o asociación, manifestación, trabajo o comercio (empresarial) y de tránsito, así como los derechos a la educación y de acceso a la justicia (tutela judicial efectiva). Estas restricciones afectaron, especialmente, a las mujeres embarazadas o en periodo de lactancia, a menores de cinco años, a personas con discapacidad, y a personas con enfermedades crónicas no transmisibles (personas con hipertensión arterial, pulmonar, insuficiencia renal, lupus, cáncer, diabetes mellitus, obesidad, insuficiencia hepática o metabólica, enfermedad cardiaca) o con algún padecimiento o tratamiento farmacológico que les genere supresión del sistema inmunológico.

\subsection{Perú}

El Estado peruano, mediante el Decreto Supremo n. ${ }^{\circ}$ 044-2020PCM y el de Urgencia n. ${ }^{\circ}$ 026-2020, ambos del 15 de marzo de este año, estableció diversas medidas excepcionales y temporales para prevenir la propagación de la COVID-19 en el territorio nacional. Con dichos decretos $-\mathrm{y}$ los que siguieron: n. ${ }^{\circ}$ 029-2020, del 20 de marzo; n. ${ }^{\circ}$ 031-2020, del 23 de marzo; n. ${ }^{\circ}$ 033-2020, del 27 de marzo; n. ${ }^{\circ}$ 034-2020 del 1 de abril; n. ${ }^{\circ}$ 037-2020 del 12 de abril; n. ${ }^{\circ} 039-2020$ del 16 de abril; n. ${ }^{\circ} 042-2020$ del 19 de abril; n. ${ }^{\text {os }} 049$ 2020 y 048-2020, ambos del 27 de abril; n. ${ }^{\circ} 083-2020-P C M$ del 9 de mayo, y n. ${ }^{\circ}$ 094-2020-PCM del 23 de mayo- se limitó o suspendió el ejercicio de diversos derechos fundamentales, con el objeto de contener los efectos de la pandemia sanitaria, para lo cual se dictaron estados de emergencia sanitaria y de emergencia nacional. 
Inclusive, se instauró «la suspensión de toda actividad que no fuera esencial, e "inmovilización social obligatoria" restringiéndose el tránsito en horas de la noche y los días domingo» (Barceló, Díaz, García y Teixeira, 2020, p. 164).

Al tenor de lo descrito, es menester precisar que algunos de los derechos fundamentales que resultaron afectados fueron los siguientes: (i) tránsito; (ii) libertad de trabajo, empresa, comercio e industria; (iii) libertad y la seguridad personal; (iv) derecho a la inviolabilidad del domicilio; (v) derecho de reunión; (vi) derechos a la educación y acceso a la justicia de manera presencial, entre otros.

Finalmente, el fundamento constitucional empleado recae en los artículos 7, 9, 135 y en el numeral 1 del artículo 137, todos de la Constitución Política del Perú, que faculta al presidente de la República para que dicte decretos de urgencia y a la Comisión Permanente del Congreso Nacional en aquellos casos de graves circunstancias que afecten la vida de la nación.

Con la emisión de los decretos ejecutivos ante la emergencia sanitaria que nos aqueja, nace el ejercicio de control constitucional por parte de los tribunales constitucionales, ya sea en virtud de una facultad constitucional explícita (análisis de regularidad), o bien derivado de la eventual restricción o suspensión del ejercicio de los derechos fundamentales que legitima su actuación represora o restitutoria ante un actuar ilícito o arbitrario. La tarea de los tribunales constitucionales surge tanto del imperativo constitucional de tutelar el adecuado ejercicio de los derechos o libertades fundamentales ante ciertos límites implícitos o explícitos derivados del dictado de estados de emergencia, alarma o excepción, como de la contingente custodia del Estado de derecho evitando su ruptura cada vez que se presenten situaciones de anormalidad (Nogueira, 2018). 
Garantizar el respeto por las normas constitucionales ante nuevos escenarios sociales que tienden a corromper el equilibrio de los poderes públicos es una misión correlativa a la funcionalidad adecuada del Estado de derecho y de los tribunales constitucionales, quienes, desde una perspectiva sustantiva, son los auténticos guardianes o custodios de la Constitución y de sus valores reconocidos.

\section{LA LIMITACIÓN O SUSPENSIÓN DEL EJERCICIO DE DERECHOS FUNDAMENTALES FRENTE A LA EMERGENCIA SANITARIA POR COVID-19. ¿CÓMO HAN ACTUADO LOS TRIBUNALES CONSTITUCIONALES?}

Sin duda, los derechos fundamentales han sido los más menoscabados con los efectos que ha traído consigo la emergencia sanitaria que atraviesa el mundo entero. Su ejercicio se ha visto limitado o restringido y, en algunos contextos, suspendido temporalmente a través del dictado de estados de excepción constitucional.

Esto conlleva que el papel de los tribunales constitucionales se active para dotar de «nuevo contenido transformador a los textos constitucionales, adaptándolos a las nuevas exigencias de la sociedad»(Pegoraro, 2017, p. 705), en tanto aquellas se presentan como escenarios anormales que buscan contenerse o regularse por parte de los poderes públicos y que dichas actuaciones son controlables por la intervención de los tribunales constitucionales.

Para ello, la revisión de regularidad constitucional de los decretos que han establecido estados de alarma, emergencia sanitaria o de excepción constitucional deviene en un imperativo protector por parte de los tribunales constitucionales, el que tiende a validar la actuación de los poderes públicos frente al orden constitucional.

El análisis de algunas sentencias dictadas por los tribunales constitucionales, relacionadas con los estragos que ha causado la 
crisis por la COVID-19, resulta obligatorio para responder esta pregunta: ¿cómo han actuado los tribunales constitucionales frente a la pandemia sanitaria? Antes de abordar el análisis conducente debemos precisar que el camino de acceso a los tribunales constitucionales ha sido variado, ya que en algunos existe una apertura directa, mientras que en otros su llegada es derivada de un proceso constitucional instaurado ante órganos judiciales de menor jerarquía.

\subsection{Corte Constitucional de Colombia}

Uno de los tribunales constitucionales más activos durante esta pandemia sanitaria ha sido la Corte Constitucional de Colombia, la que ha dictado una pluralidad de sentencias relacionadas con la revisión constitucional de decretos emitidos por los Poderes Legislativo y Ejecutivo.

Una de las sentencias más emblemáticas es la del Expediente C-145/20, donde dicha Corte analizó la validez constitucional del Decreto n. ${ }^{\circ} 417$, del 17 de marzo de 2020, por el cual «se declara un estado de emergencia económica, social y ecológica en todo el territorio nacional». En dicha sentencia constitucional se declaró exequible el decreto de mérito, estimando que el «Gobierno nacional utilizó de la manera requerida las atribuciones ordinarias para atender las dimensiones sanitarias, económicas y sociales de la pandemia desde múltiples frentes antes de declarar el estado de emergencia» (Corte Constitucional de Colombia, 2020a). Expresa, además, que las medidas legislativas que se dicten a posteriori con relación a la emergencia sanitaria deberán atenerse al contenido del artículo 215 de su Constitución Política, esto es, «que estén destinadas exclusivamente a conjurar la crisis y a impedir la extensión de sus efectos, además que se refieran a materias que tengan relación directa y específica con el estado de emergencia» (Corte Constitucional de Colombia, 2020a). 
Otra de las sentencias emblemáticas de dicha Corte Constitucional durante esta pandemia sanitaria es la emitida en el Expediente C-193/20, en que se revisó la constitucionalidad del Decreto n. ${ }^{\circ} 567$, del 15 de abril de 2020, por el que se adoptaron:

medidas para proteger los derechos fundamentales de los niños, las niñas y los adolescentes y se asignan a los procuradores judiciales de familia funciones para adelantar los procesos de adopción, como autoridades jurisdiccionales transitorias, en el marco del Estado de Emergencia Económica, Social y Ecológica [por COVID-19] (Corte Constitucional de Colombia, 2020b).

En dicha resolución se declaró inexequible el decreto de mérito, debido a que no superaba los juicios de motivación suficiente, ausencia de arbitrariedad, intangibilidad, no contradicción específica, incompatibilidad, necesidad, proporcionalidad y no discriminación, en esencia, porque:

El Decreto 567 de 2020 no contribuye a la satisfacción de los derechos fundamentales de la población; de hecho, podría poner en riesgo los derechos de los NNA debido a la alteración de las competencias de los jueces. Las medidas estudiadas no se restringen a conjurar la crisis, pues parecen perseguir otros objetivos derivados indirectamente de la misma (Corte Constitucional de Colombia, 2020b).

En tal sentido, la Corte Constitucional de Colombia realizó un control concentrado de constitucionalidad que limita el actuar del Poder Legislativo al considerarlo violatorio de diversos principios constitucionales.

\subsection{Sala Constitucional de Costa Rica}

Dicho órgano jurisdiccional que opera como tribunal constitucional ha dictado una pluralidad de sentencias relacionadas con los efectos de la emergencia sanitaria por la COVID-19, de lo 
que se tiene como dato aproximado un total de 522 resoluciones (a la fecha de elaboración del presente texto). Examinar la totalidad de las resoluciones constitucionales sería una tarea titánica que no tendría cabida pormenorizada en el presente ensayo; por ello, es prudente analizar aquellas que devienen como relevantes.

Una de las sentencias de mayor preeminencia, dada la proximidad con los grupos en situación de vulnerabilidad durante esta crisis pandémica, es la dictada en el Expediente n. ${ }^{\circ}$ 20-009015-0007-CO, el 12 de junio del presente año. La Sala Constitucional tenía que resolver la siguiente cuestión: ¿es arbitrario y lesivo del ejercicio de derechos fundamentales de las personas migrantes el retraso en las deportaciones que debe hacer la Dirección General de Migración y Extranjería, en vista de la pandemia mundial por la COVID-19? Al respecto, se determinó que:

Una persona extranjera que haya perdido su derecho a permanecer de manera legal en el país, se encuentra sujeta a la actuación de las autoridades migratorias y al respeto de lo establecido en la legislación nacional sobre su permanencia en el país, sin que la existencia de vínculos familiares con costarricenses pueda inhibir la actuación de las autoridades administrativas y las consecuencias de la pérdida de la habilitación para permanecer en el país (Sala Constitucional de Costa Rica, 2020a, p. 13).

En tal sentido, atribuyó actuación legítima a la Dirección General de Migración y Extranjería, dado que han tomado las medidas necesarias para resguardar la integridad física del personal de aquella dirección, así como de las personas que se encuentran aprehendidas en el Centro de Aprehensión Los Lagos de Heredia, de acuerdo con los lineamientos del Ministerio de Salud por la pandemia de la COVID-19; así, el retraso en las deportaciones se encuentra justificado por la emergencia sanitaria vigente, sin que este pueda ser considerado arbitrario. 
Otra sentencia a la que nos referiremos es la dictada en el Expediente n. ${ }^{\circ}$ 20-007803-0007-CO, en la que la aludida Sala Constitucional se pronunció sobre las medidas adoptadas por las instituciones de salud frente a la pandemia sanitaria por la COVID-19, específicamente respecto de comunidades indígenas (Territorio Indígena Cabécar de Alto Chirripó). Aquí se consideró que el Ministerio de Salud sí había dado atención a la comunidad indígena de Chirripó, en lo que concierne a la situación de emergencia que ha generado la pandemia producida por la COVID-19, mediante las siguientes acciones: (i) giras en la zona por parte de las autoridades itinerantes en materia de salud, con el objeto de comprobar el estado de salud; (ii) establecimiento de ubicaciones especiales para la atención de los posibles casos de COVID-19, y (iii) el cabal cumplimiento de las recomendaciones emanadas para los servicios de atención primaria en materia de salud ante la emergencia nacional.

Adicionalmente, se intensificaron las muestras (de cinco a quince diarias) para pruebas de COVID-19, y se tomaron diversas acciones basadas en los protocolos establecidos por el «Plan de trabajo abordaje de la emergencia del virus COVID-19 en territorios indígenas», elaborado por el Viceministerio de la Presidencia en Asuntos Políticos y Diálogo Ciudadano, el Ministerio de Salud, Caja Costarricense de Seguro Social y la Comisión Nacional de Asuntos Indígenas (Sala Constitucional de Costa Rica, 2020b, p. 9). De esto, se concluyó la improcedencia del recurso de amparo, al no actualizarse la vulneración al ejercicio de los derechos fundamentales de la comunidad indígena de Chirripó.

\subsection{Tribunal Constitucional español}

El Tribunal Constitucional español ha sido uno de los órganos de control constitucional más inactivos durante la pandemia sanitaria por COVID-19. Únicamente a través del auto del 30 de 
abril del presente año dictado en el Recurso de Amparo n. ${ }^{\circ} 2056$ 2020, se pronunció sobre un tópico constitucional relacionado con la pandemia, analizando brevemente la proporcionalidad de la limitación al derecho de reunión de la Central Unitaria de Traballadores/ras (CUT), derivada del dictado del Real Decreto n. ${ }^{\circ} 463 / 2020$ por el que se estableció el estado de alarma en aquel país.

Los argumentos para inadmitir el recurso de amparo en cuestión fueron en esencia los conducentes: (i) el derecho de reunión no es absoluto en términos de lo establecido en el artículo 21.1 de la Constitución española, por lo que encuentra límites constitucionalmente válidos o legítimos; (ii) el fin que persigue la limitante no solamente es legítimo, sino de cobertura constitucional ampliada, ya que tiende a proteger la integridad física y la protección a la salud, en términos de los artículos 15 y 43 de la propia Ley Fundamental; (iii) la finalidad constitucionalmente imperiosa confluye con la justificación de la declaración del estado de alarma sanitaria; (iv) existe una relación entre el fin legítimo y el objeto que pretende proteger dicha medida restrictiva, en esencia, evitar la propagación del virus y la posibilidad de contagio que haga colapsar los servicios públicos de asistencia sanitaria, y (v) la restricción en cuestión no lesiona de manera injustificada el derecho de reunión de la Central Unitaria de Traballadores/ras (CUT), por lo que debe estimarse que supera el juicio de proporcionalidad.

Dicho auto da pauta a considerar que las posibles restricciones que se generen del Real Decreto n. ${ }^{\circ} 463 / 2020$, por el que se estableció el estado de alarma en España, pueden alcanzar un cauce constitucional siempre y cuando sean legítimas y superen el principio de proporcionalidad. 


\subsection{Suprema Corte de Justicia de La nación mexicana}

Dicho Tribunal Constitucional ha recibido veinticuatro asuntos relacionados con la emergencia sanitaria que atraviesa actualmente el Estado mexicano por la COVID-19. El único pronunciamiento realizado a la fecha del presente trabajo es el emitido en la contradicción de tesis 127/2020, donde se determinó que el juez de distrito en materia de trabajo es el competente para conocer de la negativa de aplicar a favor de una persona trabajadora las medidas implementadas para mitigar y controlar los riesgos para la salud originados por la COVID-19 en los centros de trabajo (Suprema Corte de Justicia de la Nación, 2020, p. 21).

Cabe señalar que, a pesar de que dicho asunto no englobó un tema propiamente constitucional, se trata de la única resolución donde ese máximo tribunal analizó alguna cuestión relacionada con la emergencia sanitaria por la COVID-19.

En ese contexto, es posible visualizar la inacción que ha mantenido la Suprema Corte de Justicia de la Nación para revisar los diversos decretos que ha emitido el Ejecutivo Federal por conducto del Consejo de Salubridad General en términos de lo previsto en el artículo 73 (fracción XVI, numerarias $1 .^{\mathrm{a}}$ a $4 .^{\mathrm{a}}$ ) de la Constitución Federal, los mismos que han limitado explícita o implícitamente el ejercicio de derechos fundamentales en aras de mitigar los efectos de la pandemia sanitaria, y todo ello a pesar de que se han presentado diversas controversias constitucionales para cuestionar su validez constitucional e incluso la posible invasión de esferas competenciales.

\subsection{Tribunal Constitucional del Perú}

El Tribunal Constitucional del Perú, al emitir la Sentencia n. ${ }^{\circ}$ 359/2020, resolvió sobre la constitucionalidad del artículo único de la Ley n. ${ }^{\circ} 31018$ («Ley que suspende el cobro de peajes 
en la red vial nacional, departamental y local concesionada, durante el estado de emergencia nacional, declarado a causa del brote del COVID-19»). Dicho tribunal dispuso que, si bien el fin de la norma reclamada tiene como objetivo generar un beneficio económico a las actividades de transporte, consistente en eximirlas del pago de peaje, este resulta contrario al artículo 62 de la Constitución, conforme al cual los términos contractuales no se pueden modificar por leyes $\mathrm{u}$ otras disposiciones de cualquier clase. Además, se señaló que:

la ley impugnada infringe también la Constitución al prohibir la compensación correspondiente al concesionario por la afectación causada, desconociendo los derechos, las obligaciones y los mecanismos de compensación estipulados en los contratos de concesión (Tribunal Constitucional del Perú, 2020b, párr. 88).

Se declaró, en consecuencia, fundada la demanda de inconstitucionalidad presentada por el procurador público especializado en materia constitucional del Poder Ejecutivo.

Otro asunto notable de control constitucional es el emitido en el Recurso de Agravio Constitucional n. ${ }^{\circ} 243 / 2020$, en el que dicho Tribunal Constitucional analizó el alcance del contenido esencial del derecho fundamental de protección a la salud frente a la COVID-19, en términos del reconocimiento previsto en los artículos 7 y 9 de la Constitución Política. Sobre el particular, se sostuvo que:

El derecho a la salud es un derecho de especial relevancia por su especial conexión con la dignidad humana y con los derechos a la vida y a la integridad física y psíquica. La privación de la libertad personal que realiza en ocasiones el Estado, por causas legítimas y de conformidad con la Constitución y las leyes, no puede implicar la suspensión o restricción de este derecho fundamental. Por tanto, será el Estado quien asuma la responsabilidad por la salud de estas personas (Tribunal Constitucional del Perú, 2020a, párr. 7). 
Atendiendo al caso en concreto, el propio tribunal señaló que el recurrente se encuentra privado de su libertad en el Establecimiento Penitenciario Ancón II, y que es responsabilidad del Estado procurar su derecho de protección a la salud frente a la pandemia que se vive por la COVID-19. Por tanto, se analizó la proporcionalidad y razonabilidad del tratamiento brindado por el Estado a la persona privada de su libertad por la dolencia derivada de los efectos de la COVID-19, en aras de establecer si se estaban salvaguardando de manera efectiva sus derechos a la salud y a la vida.

Se concluyó -a partir del Informe Médico n. ${ }^{\circ}$ 019-2020INPE/18-EPM.ANCON II-SDSP (ff. 302), emitido por el médico cirujano Asunción Calluche Ceró- que la situación clínica del recurrente, a pesar de haber contraído COVID-19, era estable, y que se le estaba brindando tratamiento local en aislamiento. En consecuencia, se declaró infundada la acción constitucional presentada vía habeas corpus.

Sin duda, de los pronunciamientos generados por los tribunales constitucionales de referencia, podemos resolver parcialmente la interrogante formulada al inicio del presente artículo: ¿cómo han actuado los tribunales constitucionales frente a la pandemia sanitaria por COVID-19? Si bien quedan muchos espacios pendientes de resolver cuando nos acercamos al control de validez constitucional de las restricciones o limitaciones al ejercicio de derechos fundamentales que se han originado por la pandemia sanitaria, consideramos que los tribunales constitucionales - con sus notorias excepciones - han apostado por controlar las actuaciones de los Poderes Legislativo y Ejecutivo, y con ello han logrado garantizar el contenido esencial de los derechos y libertades básicas reconocidos en sus textos constitucionales, en aras de que no pierdan su vigencia y eficacia normativa o queden vaciados de contenido, lo cual no sería permisible en un Estado constitucional de derecho. 


\section{CONCLUSIONES}

Los tribunales constitucionales han evolucionado desde su configuración contemporánea a razón de la eficacia y aplicación directa de las constituciones rematerializadas, ya que las mismas dejaron de ser normas programáticas para conformarse como normas sustantivas que tienden a proteger y garantizar el ejercicio adecuado de los derechos, libertades y principios que reconocen.

La defensa de los textos constitucionales como principal función de los tribunales constitucionales ha sido un detonante para transformar su quehacer proteccionista respecto del ejercicio adecuado y efectivo de las normas de contenido prima facie. Asimismo, su misión de consolidarse como un contrapeso para evitar las actuaciones arbitrarias de los poderes públicos y privados refleja su papel protagónico en el Estado constitucional de derecho.

El tiempo y el contexto en el que se ha desarrollado el constitucionalismo contemporáneo han convenido para establecer la relevancia de los tribunales constitucionales en la defensa de los derechos fundamentales, no solo de aquellos de fuente nacional, sino también de los que emanan del derecho internacional de los derechos humanos. El pospositivismo es una teoría que, sin duda, refleja la necesidad de contar con tribunales constitucionales activos que, a través de sus determinaciones, legitimen su posición superior en la defensa de los textos fundamentales.

La custodia integral de los derechos y libertades básicas conlleva la reinvención de la interpretación constitucional con el objeto de lograr una conveniente adecuación a las nuevas exigencias sociales. La pandemia por la COVID-19 ha sido un factor determinante para entender cómo deben actuar los tribunales constitucionales a fin de cumplir con las demandas que imperan la salvaguarda eficaz de los derechos, libertades y principios constitucionales. 
Las limitaciones implícitas o explícitas al ejercicio de derechos fundamentales derivadas de la pandemia por la COVID-19 que han dictado los Poderes Legislativo y Ejecutivo deben ser revisadas por los tribunales constitucionales, en aras de contener los efectos que pudiesen vaciar su contenido esencial y que, en consecuencia, se presenten como determinaciones arbitrarias o no justificadas, eventualmente inválidas.

Finalmente, se debe precisar la claridad con la que operan actualmente los tribunales constitucionales, toda vez que, como se mencionó, no se limitan a invocar las palabras de ley o limitar sus efectos cuando estos son contrarios a los textos constitucionales; en cambio, y gracias a la interpretación constitucional principista, asumen un rol creativo que les permite analizar las exigencias sociales o contextuales; así, con base en ellas, adaptan, mutan o actualizan los textos normativos e incluso crean nuevos derechos que velen adecuadamente por las circunstancias que imperen en los Estados constitucionales de derecho.

\section{REFERENCIAS}

Aguiló, J. (2007). Positivismo y postpositivismo: dos paradigmas jurídicos en pocas palabras. Revista Doxa, (30), 666-675. https://doxa.ua.es/article/view/2007-n30-positivismo-ypostpositivismo-dos-paradigmas-juridicos-en-pocas-palabras

Alexy, R. (1993). Teoría de los derechos fundamentales. Trotta.

Atienza, M. (2017). Filosofía del derecho y transformación social. Trotta.

Barceló, D., Díaz, S., García, J. y Teixeira, M. (coords.) (2020). COVID-19 y parlamentarismo. Los parlamentos en cuarentena. Universidad Nacional Autónoma de México. https://biblio. 
juridicas.unam.mx/bjv/detalle-libro/6225-covid-19-yparlamentarismo-los-parlamentos-en-cuarentena

Bernal, C. (2003). Estructura y límites de la ponderación. Revista Doxa, (26), 225-238. https://doxa.ua.es/article/view/2003-n26estructura-y-limites-de-la-ponderacion

Carbonell, M. (2008). El principio de proporcionalidad y la interpretación constitucional. Ministerio de Justicia y Derechos Humanos.

Corte Constitucional de Colombia (2020a). Expediente C-145/20. Bogotá: 20 de mayo de 2020. https://www.corteconstitucional. gov.co/relatoria/2020/C-145-20.htm

(2020b). Expediente C-193/20. Bogotá: 24 de junio de 2020. https://www.corteconstitucional.gov.co/relatoria/2020/C-193-20. htm

Dworkin, R. (2019). El derecho de las libertades. La lectura moral de la Constitución Norteamericana. Palestra.

Ferrajoli, L. (2014). La democracia a través de los derechos. El constitucionalismo garantista como modelo teórico y como proyecto político. Trotta.

Ferrer Mac-Gregor, E. (2017). Panorámica del derecho procesal constitucional y convencional. Marcial Pons.

Ferrer Mac-Gregor, E. y Zaldívar, A. (coords.) (2008). La ciencia del derecho procesal constitucional. Estudios en homenaje a Héctor Fix-Zamudio en sus cincuenta años como investigador del derecho. Universidad Nacional Autónoma de México.

Gascón, M. (coord.) (2014). Argumentación jurídica. Tirant lo Blanch.

Kelsen, H. (2017). La garantía jurisdiccional de la constitución. Centro de Estudios Carbonell. 
MacCormick, N. (2018). Razonamiento jurídico y teoría del derecho. Palestra.

Nogueira, H. (2018). Teoría y dogmática de los derechos fundamentales. Universidad Nacional Autónoma de México.

Pino, G. (2018). El constitucionalismo de los derechos. Estructura y límites del constitucionalismo contemporáneo. Zela.

Pegoraro, L. (2017). Derecho constitucional comparado. Tirant lo Blanch.

Prieto, L. (2013). El constitucionalismo de los derechos. Ensayos de filosofía jurídica. Trotta.

Sagüés, N. (2011). Control de constitucionalidad y control de convencionalidad. A propósito de la «constitución convencionalizada». Parlamento y Constitución. Anuario, (14), 143-152. https://dialnet.unirioja.es/servlet/articulo? codigo $=4259243$

Sala Constitucional de Costa Rica (2020a). Expediente n. ${ }^{\circ} 20$ 009015-0007-CO. San José: 12 de junio de 2020. https://nexuspj. poder-judicial.go.cr/document/sen-1-0007-291372//1/_score/ undefined/9

(2020b). Expediente n. ${ }^{\circ}$ 20-00703-0007-CO. San José: 12 de junio de 2020. https://nexuspj.poder-judicial.go.cr/document/ ext-1-0007-282007/undefined/0/_score/undefined/6

Silva, F. (2012). Deber de ponderación y principio de proporcionalidad en la práctica judicial. Miguel Ángel Porrúa.

Suprema Corte de Justicia de la Nación (2020). Contradicción de tesis 127/2020. Ciudad de México: 8 de julio de 2020. https:// www2.scjn.gob.mx/consultatematica/paginaspub/DetallePub. aspx?AsuntoID $=272196$ 
Tribunal Constitucional español (2020). Recurso de Amparo n. ${ }^{\circ}$ 2056-2020. Madrid: auto del 30 de abril de 2020. https://delajusticia.com/wp-content/uploads/2020/05/20202056ATC.pdf

Tribunal Constitucional del Perú (2020a). Recurso de Agravio Constitucional n.o 243/2020. Lima: 18 de junio de 2020. http://181. 177.234.7/buscarRes/public/resolucionjur?filtro $=$ F\&search $=\mathrm{CO}$ VID-19\&demandante $=\&$ demandado $=\&$ numexpediente $=\&$ anoi ngreso $=\&$ idtipoproces $\mathrm{o}=0 \&$ anopublica $=\& p g=1$

(2020b). Sentencia n. ${ }^{\circ}$ 359/2020. Lima: 25 de agosto de 2020. http://181.177.234.7/buscarRes/public/resolucionjur?filtro= F \& se arch $=$ COVID $-19 \&$ demand ante $=\&$ demand ado $=$ $\&$ numexpediente $=\&$ anoingreso $=\&$ idtipoproceso $=$ $0 \&$ anopublica $=\& p g=1$

Zagrebelsky, G. (2020). Manual de derecho constitucional. Zela. 